\title{
Root cause analysis of laboratory turnaround times for patients in the emergency department
}

\author{
Christopher M.B. Fernandes, MD; ${ }^{*}$ Andrew Worster, MD; ${ }^{* \dagger}$ Stephen Hill, $\mathrm{PhD} ;{ }^{\ddagger \S}$ \\ Catherine McCallum, ART; ${ }^{\ddagger}$ Kevin Eva, $\mathrm{PhD}^{\dagger}$
}

\begin{abstract}
Introduction: Laboratory investigations are essential to patient care and are conducted routinely in emergency departments (EDs). This study reports the turnaround times at an academic, tertiary care ED, using root cause analysis to identify potential areas of improvement. Our objectives were to compare the laboratory turnaround times with established benchmarks and identify root causes for delays.

Methods: Turnaround and process event times for a consecutive sample of hemoglobin and potassium measurements were recorded during an 8-day study period using synchronized time stamps. A log transformation (In [minutes + 1]) was performed to normalize the time data, which were then compared with established benchmarks using one-sample $t$ tests.

Results: The turnaround time for hemoglobin was significantly less than the established benchmark $(n=140, t=-5.69, p<0.001)$ and that of potassium was significantly greater $(n=121, t=$ $12.65, p<0.001)$. The hemolysis rate was $5.8 \%$, with $0.017 \%$ of samples needing recollection. Causes of delays included order-processing time, a high proportion $(43 \%)$ of tests performed on patients who had been admitted but were still in the ED waiting for a bed, and excessive laboratory process times for potassium.

Conclusions: The turnaround time for hemoglobin $(18 \mathrm{~min}$ ) met the established benchmark, but that for potassium (49 $\mathrm{min}$ ) did not. Root causes for delay were order-processing time, excessive queue and instrument times for potassium and volume of tests for admitted patients. Further study of these identified causes of delays is required to see whether laboratory TATs can be reduced.
\end{abstract}

Key words: laboratory, turnaround times, quality improvement, root cause analysis

RÉSUMÉ

Introduction : Les examens de laboratoire sont essentiels aux soins des patients et sont routiniers à l'urgence. Cette étude fait état des délais d'exécution à l'urgence d'un établissement universitaire de soins tertiaires en utilisant l'analyse des causes fondamentales pour identifier les points d'amélioration possible. Nos objectifs étaient de comparer les délais d'exécution en laboratoire aux délais de référence établis et d'identifier les causes fondamentales des retards.

\footnotetext{
*Emergency Medicine, Hamilton Health Sciences and McMaster University, Hamilton, Ont. tDepartment of Clinical Epidemiology And Biostatistics, McMaster University

¥Hamilton Regional Laboratory Medicine Program, Hamilton, Ont.

$\S$ Department of Pathology and Molecular Medicine, McMaster University
}

Received: Aug. 19, 2003 ; final submission: Nov. 21, 2003; accepted: Dec. 2, 2003

This article has been peer reviewed.

Can J Emerg Med 2004;6(2):116-22 
Méthodes: On a relevé les délais d'exécution et de traitement d'un échantillon consécutif de mesures de l'hémoglobine et du potassium pendant une période d'étude de huit jours à l'aide de marques d'horodatage synchronisées. Une modification a été apportée au registre (In [minutes + 1]) pour normaliser les données chronologiques, qui ont été ensuite comparées aux données de référence établies à l'aide de tests $t$ à un échantillon.

Résultats : Le délai d'exécution pour l'hémoglobine était beaucoup plus court que le délai de référence établi $(n=140, t=-5,69, p<0,001)$ et celui du potassium était beaucoup plus long $(n=$ $121, t=12,65, p<0,001)$. Le taux d'hémolyse était de $5,8 \%$ et il fallait refaire la collecte de $0,017 \%$ des échantillons. Les causes de retard comprenaient le temps de traitement de la commande, le pourcentage élevé (43\%) de tests effectués pour des patients admis mais attendant toujours un lit à l'urgence et le temps de traitement excessif en laboratoire pour le potassium.

Conclusions : Le délai d'exécution pour l'hémoglobine (18 min.) correspond au délai de référence établi, mais pas celui pour le potassium (49 min.). Les causes fondamentales des retards étaient le temps de traitement de la commande, la file d'attente trop longue, le temps d'utilisation des instruments pour le potassium et le volume de tests pour les patients admis. Une étude plus approfondie des causes de retard identifiées sera nécessaire pour déterminer si les délais d'exécution en laboratoire peuvent être raccourcis.

\section{Introduction}

In this time of emergency department (ED) overcrowding, efficient process and patient management during the ED visit may lessen the impact of overcrowding on strained resources. ${ }^{1,2}$ Shortened waiting times for test results could potentially allow patients to be discharged in a more timely fashion, making ED stretchers available for patients waiting in hallways and on ambulance gurneys. Laboratory turnaround time (TAT), the time from physician ordering of an investigation to the return of test results, is a key measure of an important ED process. Many believe that prolonged laboratory TATs cause treatment delays and protracted ED stays. ${ }^{3}$

The College of American Pathologists Q-Probes Study summarized data from 700 institutions and 40000 specimens per analyte. ${ }^{4}$ It identified TAT from phlebotomy to reporting of results as the most important performance measure for stat laboratory testing and documented a median inter-institutional TAT for hemoglobin of 25 minutes and a median TAT for potassium (which is considered a surrogate for all tests analyzed on serum or plasma) of 36 minutes. The Q-Probes report focused on laboratory performance and did not consider the interval from physician ordering to phlebotomy. This additional interval may be important when trying to determine whether causes of delay relate to the ED, the laboratory, or both. ${ }^{5,6}$

The objectives of this study were to identify time intervals from physician ordering to result reporting for hemoglobin and potassium assays, to compare these times with established benchmarks from the Q-Probes Study and to identify the root causes of delays.

\section{Methods}

\section{Design}

Root cause analysis is an investigative method that tracks each of the relevant steps in a process and traces them back from the end failure to determine the initial or root cause. ${ }^{7}$ The 3 steps in RCA are to identify potential causes of delay using a cause-and-effect diagram, to collect data related to these potential causes, and to identify root causes based on these data that should clarify the impact of the causes on the particular process. A key component is the use of Pareto analysis, which specifies that $80 \%$ of the problem will often be the result of $20 \%$ of the causes and encourages the analyst to focus on the "vital few" rather than the "useful many." ${ }^{8}$ Wilson and colleagues provide an excellent overview of root cause analysis for interested readers. $^{7}$

\section{Setting}

This study was conducted at Hamilton General Hospital Emergency Department of Hamilton Health Sciences, an acute care tertiary teaching hospital affiliated with McMaster University, Hamilton, Ont. The hospital serves as a regional cardiovascular, neurosciences and Level I adult trauma centre. The ED, staffed by full-time emergency physicians, has an annual volume of 39500 patient visits, $50.8 \%$ of which are triaged as emergent or urgent (i.e., CTAS Levels I and III), ${ }^{9}$ and a $17.4 \%$ admission rate.

\section{Sampling}

This cross-sectional study examined TATs for all stat hemoglobin and potassium measurements during an 8-day 
period. Potassium analyses were performed using a Roche Integra 700 (Roche Diagnostics, Laval, Que.), and hemoglobin analyses were performed using a Coulter Gen-S (Beckman Coulter, Inc, Brea, Calif.). Blood samples from critically ill patients were excluded because of concerns about the accuracy of collection-time documentation in such cases. Blood tests submitted as "routine" were also excluded because our ED samples are ordered as "stat" or "urgent," and because benchmarks established in the QProbes Study were derived from stat, not routine, testing. Patient identifiers were removed from each sample and replaced by sequential numeric identifiers to ensure confidentiality.

The hemolysis rate was recorded because hemolysis may induce falsely elevated potassium levels, at times necessitating repeat collection of blood specimens. The proportion of potassium samples hemolyzed is reported as percent of total potassium samples.

\section{Data collection}

A flow chart was created to identify key steps in the laboratory process (Fig. 1). The key steps and times for this study were: physician orders test on paper (T1); bedside nurse processes physician orders and enters sample information in the hospital information system (T2); bedside nurse collects blood sample (T3); sample placed in tube system and transported to laboratory (T4); sample logged into the laboratory computer (accession time $=\mathrm{T} 5$ ) and queued for placement in the instrument; samples placed in instrument (T6); results reported on the hospital information system (T7). This allowed for the measurement of 7 event times (i.e., 6 time intervals [Table 1]) and overall TAT.

T1 through T6 were registered on the data collection form via synchronized time stamps, and T7 was collected from the hospital information system. Overall TAT incorporated all of these, as per the Q-Probes Study, with the addition of the physician-order time (T1). For the data collection period, every effort was made to blind the ED and laboratory staff to the objectives of the study.

\section{Analysis}

Sample size determination for this study was based on a previous 1-week study of stat hemoglobin and potassium TATs. ${ }^{10}$ Central tendency and dispersion were described using median values and interquartile ranges (IQRs). Where appropriate, $95 \%$ confidence intervals were calculated to illustrate data precision. A log transformation (ln [minutes +1$]$ ) was performed to normalize TAT data. Transformed data were compared with data from the Q-
Probes Study using 1-sample $t$ tests minus T1. Our ethics review board considered this a quality assessment study involving no human subjects or experiments and ruled it exempt from formal approval.

\section{Results}

Of 837 patients registered in the ED during the study period, 207 had their hemoglobin or potassium measurements checked. Overall, 43\% of the 207 samples were drawn on patients who had been admitted but were still in the ED waiting for a bed. Figure 2 summarizes eligible, excluded and missed patients (i.e., patients not identified by the laboratory as having had these measurements checked), and shows that 147 stat samples were analyzed. The median TAT was 18 (IQR 13-26) minutes for hemoglobin and 49 (IQR 42-58) minutes for potassium. Table 1 shows that hemoglobin TAT was significantly less than the Q-Probes benchmark (18 v. $25 \mathrm{~min} ; p<0.001)$ and the potassium TAT was significantly greater (49 v. $36 \mathrm{~min} ; p<$ $0.001)$. Our data reveal that $75 \%$ (105/140) of hemoglobin samples and $10.7 \%(13 / 121)$ of potassium samples met the Q-Probes benchmark time. Hemolysis was noted in 7 potassium samples $(5.8 \%)$, but only 2 of these required repeat sample collection.

Root cause analysis demonstrated 3 root causes of delay - order processing for both hemoglobin and potassium, volume of tests for admitted patients, and queue and instrument times for potassium - although we could not determine the proportionate contribution of these 3 main causes to the overall delay. A barrier analysis (Table 2) provides insight into the contribution of the work environment and existing processes to TAT delays.

\section{Discussion}

These data show that the median TAT for hemoglobin met the Q-Probes benchmark in $75 \%$ of cases, but this was the case for potassium in only $10.7 \%$ of cases. The main contributors to delay were processing times, admitted-patient testing and laboratory queue and instrument times. Unlike previous studies, hemolysis was not a significant contributor to laboratory delays. ${ }^{10}$

\section{Test processing times}

Order processing is identified as a root cause of delay for both tests. The Leapfrog Group ${ }^{11}$ recently identified computerized physician-order entry as an important mechanism to improve patient safety. As more hospitals move to computerized physician-order entry, processing times 


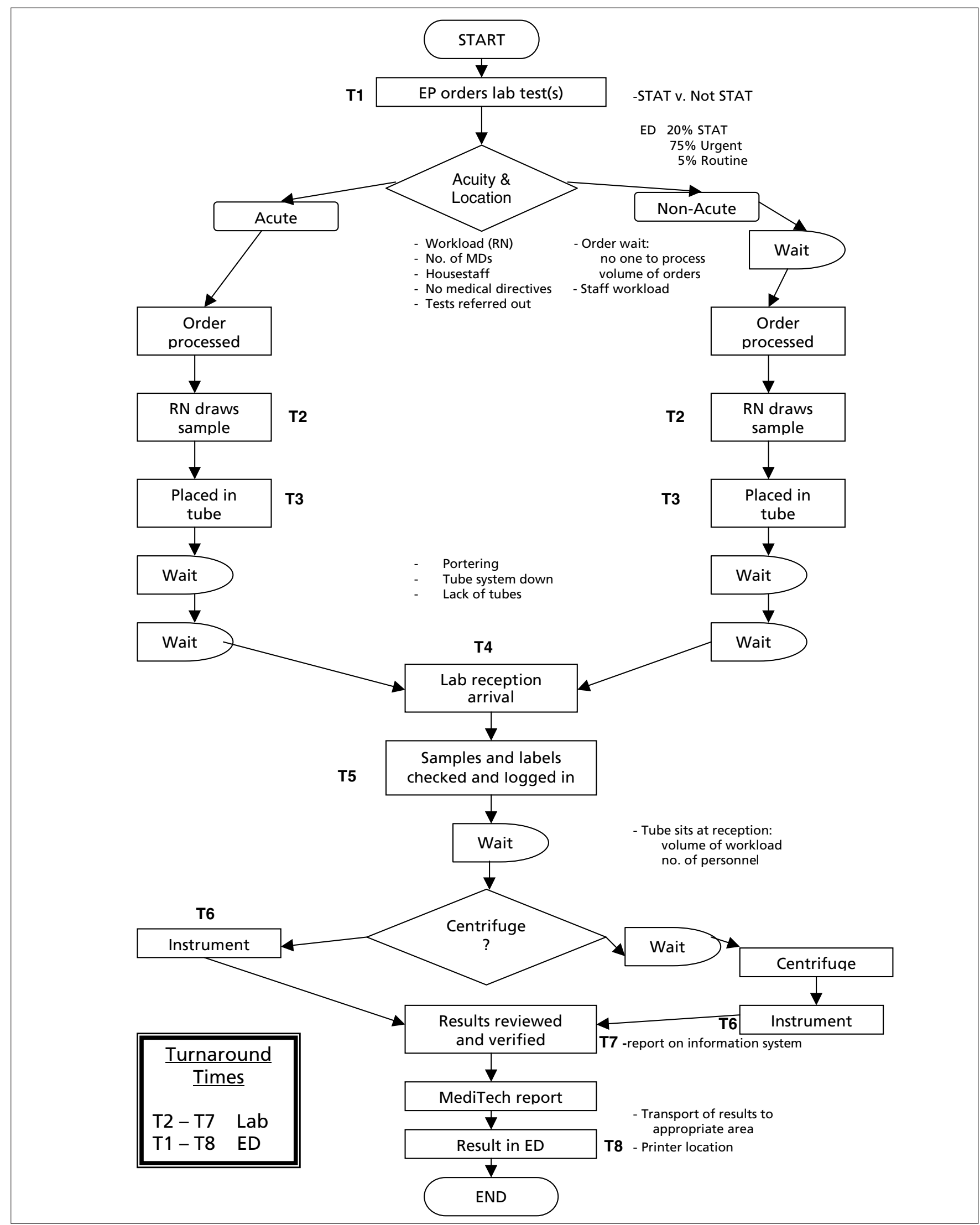

Fig. 1. Key steps in the laboratory process 
should decrease and patient safety should improve, based on the elimination of illegible physician orders and transcription errors.

Although Q-Probes did not assess time from order to processing and collection, we believed it could be an additional cause of delay. Our root cause and barrier analysis suggests that reliance on ED nurses having the time to perform phlebotomy may further prolong the processing. It may be that use of dedicated personnel for phlebotomy would reduce order-processing time. Excessive queue and instrument times suggest the need for process change in the laboratory for chemistry analysis. Finally, the workload of caring for admitted patients who are still in the ED (43\% of stat ED lab tests in this study) slows processing of true "stat" tests on non-admitted patients by increasing total requests being processed.

\section{Admitted-patient testing}

As reported in a previous study, the volume of tests for admitted patients contributed to prolonged order-processing time. ${ }^{10}$ Admitted-patient testing volume has grown significantly along with the severity of ED overcrowding; in our ED, admitted patients routinely occupy $25 \%-100 \%$ of ED stretchers. This contributes to loss of ED productivity because the time that ED staff spend with stable admitted patients detracts from the evaluation and management of incoming acutely ill patients. It is common for the laboratory to view any test routed from the ED as a "stat" test (including those from stable admitted patients). This is likely to have a further impact on ED stat test TATs because an increasing number of ad- mitted-patient tests, which are commonly processed as stat, displace the test specimens taken from newly arrived acute ED patients.

\section{Sample processing}

The sample-processing time for potassium is expected to be a minimum of 15 minutes because of the need for centrifuge. Use of whole-blood analyzers would preclude centrifuge, although these instruments offer a smaller menu of tests than large automated multi-analyte instruments.

Instrument time, depending on the machine, can be expected to be a minimum of 8.5-10 minutes, depending on the rate-limiting step. Multi-analyte laboratory instruments generally hold results on a sample until all results are ready to be reported. Thus, the analytical time is that of the longest test requested on each sample. Taken together, there is room for improvement in the sample processing and instrument times.

\section{Limitations}

A limitation of this study could have been a Hawthorne effect introduced by ED staff when recording the event times, although efforts were made to keep the staff unaware of the objectives. Synchronized electronic time stamps were employed to ensure integrity of the recorded times. Given that the study was conducted over 8 days with rotating ED staff, it is unlikely that a concerted effort to falsify the recorded times was made. External validity is also uncertain, and our findings may not apply to all EDs. This study measured hemoglobin and potassium as reflections of the system, without evaluating the need for these

\section{Table 1. Sample processing time intervals for laboratory during} study period, and comparison with benchmark times

\begin{tabular}{lccc} 
& & \multicolumn{2}{c}{$\begin{array}{c}\text { Sample taken; median time, min* } \\
\text { (and IQR) }\end{array}$} \\
\cline { 3 - 4 } Variable & $\begin{array}{c}\text { Time } \\
\text { intervalt }\end{array}$ & Hemoglobin & Potassium \\
\hline Key stept & & & \\
Order processing & T1-T2 & $9(1-17)$ & $9(3-20)$ \\
Collection & T2-T3 & $2(0-7)$ & $2(0-7)$ \\
Transit & T3-T4 & $4(2-8)$ & $4(2-8)$ \\
Accession & T4-T5 & $1(0-2)$ & $1(0-2.25)$ \\
Queue & T5-T6 & $2(1-4)$ & $22(18.25-26)$ \\
Instrument & T6-T7 & $4(2-7)$ & $14(11.75-19)$ \\
Turnaround time & T2-T7 & $18(13-26)$ & $49(42-58)$ \\
Q-Probes ${ }^{4}$ benchmark time & & 25 & 36 \\
\% that met Q-Probes & & & 10.7 \\
benchmark & & 75.0 & \\
\hline
\end{tabular}

*Unless otherwise specified.

tFor a more complete description of the Key steps and Time intervals see Methods section.

IQR = interquartile range 
tests. Elimination of unnecessary tests may ultimately be the most efficient improvement in laboratory TATs.

There are a number of opportunities for further research, including seeing whether changes to these root causes improve the system, if implementation of an improved system will allow favourable function of computerized physician-order entry, if ED length of stay for acute patients will be affected, and if reduced TAT will result in quicker decision-making.

\section{Conclusions}

In this study, the TAT for hemoglobin (18 min) met the established benchmark, but that for potassium (49 min) did not. Root causes of delay were order-processing time; excessive queue and instrument times for potassium and volume of tests for admitted patients. Further study of these identified causes of delays is required to see whether laboratory TATs can be reduced.

Table 2. Barrier analysis of root causes for laboratory delays

Target: Emergency department length of stay for acute patients

\begin{tabular}{lll}
\hline Threat & \multicolumn{1}{c}{ Barrier } & \multicolumn{1}{c}{ Analysis } \\
\hline $\begin{array}{l}\text { 1. Order processing time interval } \\
\text { 2. Long queue and instrument time intervals }\end{array}$ & Current practice & $\begin{array}{l}\text { No added value (i.e., does not alter quality } \\
\text { of the test from the patient's point of view) }\end{array}$ \\
$\begin{array}{l}\text { 3. Volume of stat tests for admitted patients } \\
\text { being held in the ED }\end{array}$ & None & $\begin{array}{l}\text { Process needed to track these times regularly } \\
\text { in the laboratory }\end{array}$ \\
\hline
\end{tabular}

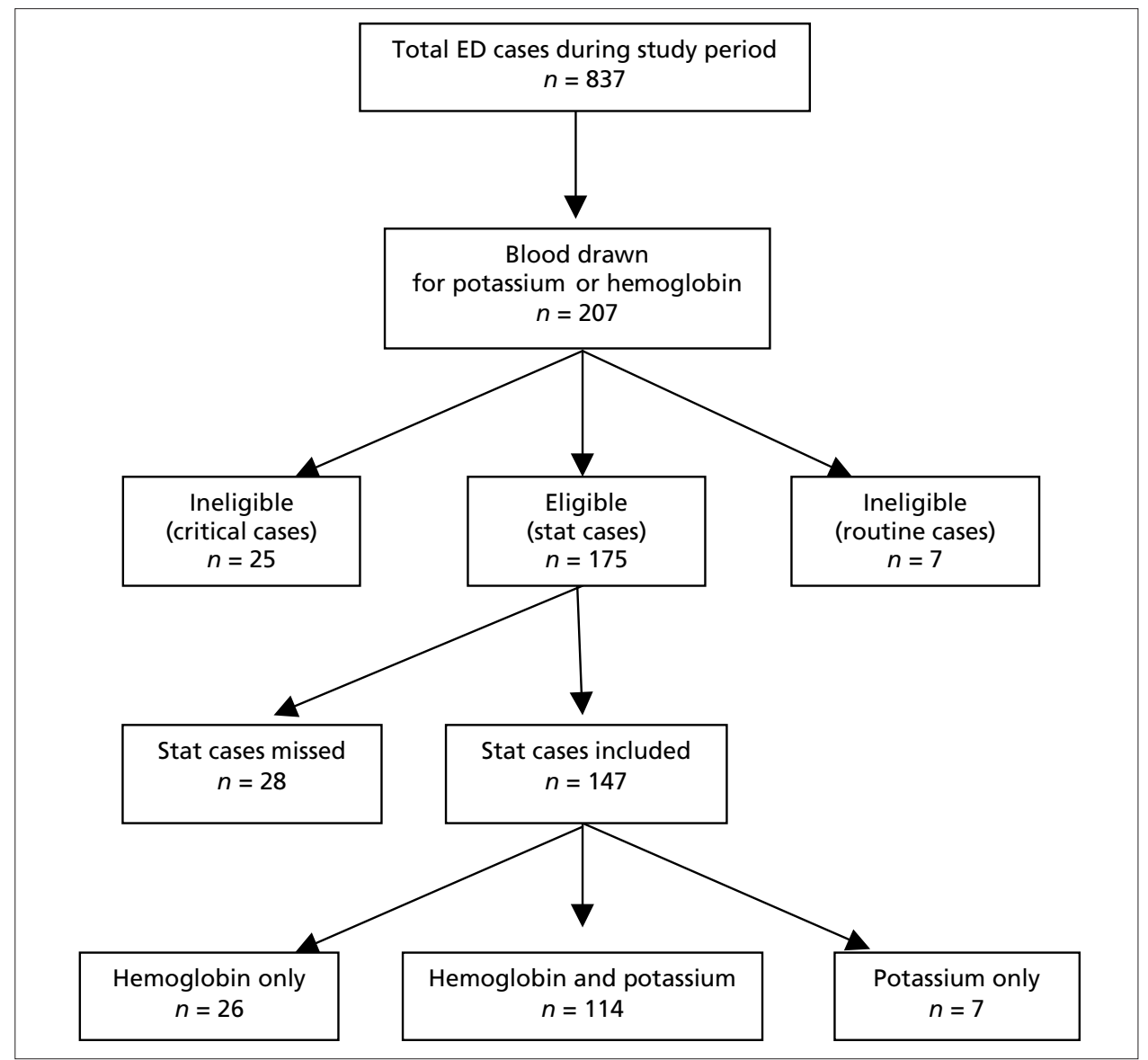

Fig. 2. Flow chart of emergency department patients for whom potassium or hemoglobin measurements were tested 
Competing interests: None declared.

\section{References}

1. Kaplan R, Norton D. The strategy-focused organization. Boston: Harvard Business School Publishing Corporation; 2001.

2. Joint Commission tackles emergency department overcrowding. ACEP News 2003;May:1-2.

3. Steindel SJ, Howanitz PJ. Physician satisfaction and emergency department laboratory test turnaround time. Arch Pathol Lab Med 2001;125:863-71.

4. Howanitz PJ, Steindel SJ, Cembrowski GS, Long TA. Emergency department stat test turnaround times. Arch Pathol Lab Med 1992;116:122-8.

5. Howanitz PJ, Cembrowski GS, Steindel SJ, Long TA. Physician goals and laboratory test turnaround times. A College of American Pathologists Q-Probes study of 2763 clinicians and 722 institutions. Arch Pathol Lab Med 1993;117:22-8.

6. Howanitz JH, Howanitz PJ. Laboratory test results. Timeliness as a quality attribute and strategy. Am J Clin Pathol 2001; 116:311-5.
7. Wilson PF, Dell LD, Anderson GF. Root cause analysis: a tool for total quality management. Milwaukee: American Society for Quality Control;1993. p. 59-72, 131-50.

8. Juran JM. Juran on planning for quality by design. New York: The Free Press; 1988.

9. Beveridge R, Clarke B, Janes L, Savage N, Thompson J, Dodd G, et al. Canadian Emergency Department Triage and Acuity Scale: implementation guidelines. Can J Emerg Med 1999;1(3 Suppl). Available: www.caep.ca/002.policies/002-02.ctas.htm

10. Fernandes CMB, Walker R, Price A, Marsden J, Haley L. Root cause analysis of laboratory delays to an emergency department. J Emerg Med 1997;15:735-9.

11. The Leapfrog Group Web site [Internet]. Available: www.leapfroggroup.org (accessed 2004 Feb 6).

Correspondence to: Dr. Christopher Fernandes, Professor and Head, Emergency Medicine, Hamilton Health Sciences/McMaster University, 237 Barton St. E, Hamilton ON L8L 2X2; fax 905 528-0512, christopher_fernandes@sympatico.ca 